Saudi Journal of Humanities and Social Sciences

Abbreviated Key Title: Saudi J Humanities Soc Sci

ISSN 2415-6256 (Print) | ISSN 2415-6248 (Online)

Scholars Middle East Publishers, Dubai, United Arab Emirates

Journal homepage: https://saudijournals.com

Review Article

\title{
Kôngo and Hindu Perceptions of Reincarnation and their Reinterpretation of African Cultures
}

\author{
Kiatezua Lubanzadio Luyaluka, Ph. D. (hon) ${ }^{1^{*}}$ \\ ${ }^{1}$ Institut des Sciences Animiques Kinshasa, Democratic Republic of Congo
}

DOI: $\underline{10.36348 / \mathrm{sjhss} .2022 . v 07 i 01.004}$

| Received: 02.12.2021 | Accepted: 06.01.2022 | Published: 11.01.2022

*Corresponding author: Kiatezua Lubanzadio Luyaluka, Ph. D. (hon)

Institut des Sciences Animiques Kinshasa, Democratic Republic of Congo

\section{Abstract}

The issue of reincarnation has always been handled as an answer to the question: do Africans believe in reincarnation? This paper shows that the main issue should rather be: do Africans believe in the law of reincarnation? Through the analysis of the differential cosmological conceptions of reincarnation in Kôngo culture and Hinduism the author arrives to the conclusion that contrary to Hinduism reincarnation is not a law in the African Kôngo worldview. This conclusion leads the author to revisit what is assumed to be the doctrine of reincarnation or transmigration of soul, in some African cultures and to show that it alludes rather the transmigration of spirit, the natural means for an ancestor to come back through a sharing of his qualities with a newborn and even for being his protector.

Keywords: Reincarnation; Bukôngo; Hinduism Advantin; transmigration of spirit; transmigration of soul.

Copyright () 2022 The Author(s): This is an open-access article distributed under the terms of the Creative Commons Attribution 4.0 International License (CC BY-NC 4.0) which permits unrestricted use, distribution, and reproduction in any medium for non-commercial use provided the original author and source are credited.

\section{INTRODUCTION}

The issue of the existence of the doctrine of reincarnation in African traditional religion (ATR) has so far been handled to answer the question: do Africans believe in reincarnation? (Jimoh, 2012; Ogbujah, 2008; Ọsanyìnbí \& Falana, 2016). This approach distorts the problematic and often arrives to the conclusion that reincarnation, or transmigration of soul, is one of the tenets of African cultures. A survey illustrates this trend: "In most countries surveyed, at least three-in-ten people believe in reincarnation, which may be related to traditional beliefs in ancestral spirits" (PEW FORUM ON RELIGION \& PUBLIC LIFE. 2010, P. 33). However, we intend, in this paper to start by showing that the doctrine of reincarnation is not held in the same manner in Africa and in India.

The affirmation of the existence of a differential in the conceptions of reincarnation in India and in Africa is not new; it was declared, for instance, by Asante (2009a) who distinguishes two ideas in the African concept of reincarnation:

The first is that this belief in reincarnation is firmly held in most of Africa. The second one is that the African idea of reincarnation differs from the Asian idea; throughout Africa, people believe that humans who die return to the Earth in different human forms, but not, as is found in India, as animals (Asante, 2009a, pp. 51-52).

The originality of our approach is that we intend to establish this difference in the perspective of answering the following question: is reincarnation a law according to the African worldview? As African cultures are various, we will basically resort to Kôngo religion, Bukôngo in this demonstration because it will be shown that this religion is the continuation of the solar religion that characterized the civilizations of ancient Egypt and Sumer, thus it constitutes the original trend of ATR. For the purpose of our demonstration two schemes will be used to establish the existence of differential perceptions of the concept of reincarnation in Hinduism and in Bukôngo:

- The cosmological approach: through the comparative study of these two cultures we will show that the law of reincarnation is not in harmony with the cosmology of Bukôngo which rather dictates the law of the progression of the dead towards higher planes of existence.

- The metaphysical approach: after having established the difference between the doctrine of reincarnation, as the transmigration of soul, and the doctrine of the transmigration of spirit, we will use ethno-linguistic to demonstrate that what is assumed to be the 
doctrine of reincarnation in Bukôngo is rather a transmigration of spirit, the process through which an ancestor shares his qualities with a new born and even becomes his protector.

The conclusion thus reached through comparative study of Hinduism and Bukôngo will enables us to revisit what is assumed to be the doctrine of reincarnation in some African cultures; thus comparative study will also allow us to demonstrate that according to the light thrown by Bukôngo on this issue, what is assumed to be a transmigration of soul in Africa is rather consistent with the phenomenon of the transmigration of spirit.

Finally, the belief in reincarnation will not be denied any existence in Africa, but its presence in the various cultures of Africa will be demonstrated to be the exception to the general law of the progression of the dead towards higher planes of existence.

\section{Bukôngo as the paragon of african traditional religion \\ The use of comparative study in our} demonstration impels the need to rely a one African culture as the standard to the appreciation of others. The basic use of Bukôngo in our demonstration is justified by the correlation of its theological doctrines with the religion of ancient Egypt and Sumer as can be seen in the following proven facts:

- Bukôngo shares the same epistemology with the ancient civilizations of Egypt and Sumer (Luyaluka, 2016); an epistemology, called solar, due to its focus on the divine, and epitomized by the freedom the soul from the body. This freedom is affirmed in Egypt by the depiction of the soul as a bird hovering over man's body or his corpse (Maspero, n.d.) and is evidenced in the case of Sumer by Kramer (1981) who writes: "the soul flies from Dumuzi's body 'like falcon flies against another bird"' (p. 297).

- The doctrine of the freedom of soul has as corollary its immortality affirmed by the Egyptian book of the dead and is seen in Bukôngo in the statement of Wing (1956): "the name never dies, in this it resembles to the soul or môyo" (p. 16). Another consequence of the freedom of the soul is the continuity of life in the beyond; it reveals the existence of higher planes of existence which naturally implies a hierarchical perception of theism where a Supreme Being thrones above a demiurgic creator and the Verb, a principle which participate in the process of creation along with the creator (see table) (Luyaluka, 2017a).

- Hierarchical theism has been demonstrated to be consistent with the systematic natural theology developed by the Institut des Sciences Animiques (ISA) through the use of a the kemetic cosmological argument (KCA); thus the KCA is the scientific statement of solar religion (Luyaluka, 2014).
Moreover the KCA results in a mathematically demonstrable Newtonian cosmology which is consistent with the Egyptian view of the cosmos depicted by the famous scene of Nut, Shu (Luyaluka, 2017b).

- As Bukôngo is immersed in solar epistemology and as it has been shown to be wholly consistent with the systematic natural theology developed by the KCA (Luyaluka, 2014), this trend of ATR is the continuation of the solar religion advocated by the Egyptians and the Sumerians and whose main features are:

- The preponderance of the divine mystery teachings over the human (i.e. civil and martial teachings) in the initiatory system.

- The hierarchical nature of the theism.

- The notion of the presence of fullness of the divinity (the Verb) in celestial and human beings epitomized as the conjunction in them of the male and the female principles.

- The existence of Spirits.

- The belief in the necessity of the intercession of the ancestors.

It is worthy to note here that, thanks to the $\mathrm{KCA}$, all these basic characteristics of solar religion can be established logically by starting from an empirical basis (the existence of individualities in this universe) coupled with the use of the law of causality or the principle of sufficient reason; thus, as we said above, the KCA constitutes the systematic natural theology of solar religion (Luyaluka, 2014 \& 2017a).

It follows that the immersion of the various trends of traditional Africa in the same solar epistemology and the southward migrations of African ethnics imply that solar religion is the original version of ATR; thus all the trends of ATR can be understood as the devolutions of solar religion, i.e., of Bukôngo which is its continuation. These devolutions are the results of differential nature of the southward migrations of African ethnics, the misrepresentation of their theism by Western missionaries, the destruction of initiatory schools around the years 1930s and the oblivion of the hierarchy of theism which ensued (Luyaluka, 2017a). Therefore the conclusions reached for Bukôngo can be generalized mutatis mutandis to other African ethnics.

\section{Comparative table of hierarchical theisms}

\section{Reincarnation in Hinduism}

According to Izibili (2008), the word 'reincarnation' is un-African (p. 105). It is a word made of two parts: re and incarnation. It implies the fact of incarnating anew; however, there cannot be a reincarnation without a previous de-incarnation; thus a soul is supposed to leave a body for another one. As the word reincarnation has been taken from foreign 
cultures, we will examine its nature in Hinduism where it is an established religious tenet.

In Hindu Advantin reincarnation is a means to escape the illusory power of the maya "the great veiling of the true, Unitary Self" which impedes man to experience moksha "the enlightened realization that reality is one" (Meister, 2005, p. 48). Contrary to its perception in solar religion, the soul (atman) in this Eastern culture is perceived as a natural indweller of a body, "the eternal principle within each individual" (Armstrong, 1993, p. 21).

Reincarnation thus defined implies a migration of the soul from one body to another; the deserted body ceases to live, while the soul abides in the new incarnation. Therefore, reincarnation always implies a transmigration of soul; though this last phenomenon is not restricted to reincarnation, as it is also involved in what is called out-of-body-experience.

A fundamental nature of reincarnation in Hindu Advantin is that it is a law dictated by the cosmology of this Eastern religion. This religion insists that the good and the evil that we see in this plane of existence and others are merely an illusion (maya), "or at best transitory" (Wayne, 1991, p. 2). To explain this illusory nature, the maya, Evans-Wentz (1969) wrote:

All possible conditions, states or realm of sangsarique existence: heaven, hell, and worlds are entirely dependent phenomena, in other words are nothing but phenomena.

"(...) All phenomena are transient, illusory, unreal, nonexistent, except in the sangsarique mind perceiving them. (Evans-Wentz, 1969, p. 57).

According to the teaching of Hindu Advantin the misfortune of man stems from the fact that he wishes to enjoy the maya rather than to get rid of it; it is thus clear that the purpose of this existence of man, according to this Hindu view, is to get rid of this illusion. However, when a man dies and goes in the beyond, he finds himself in a greater illusion that Evans-Wentz (1969) defined as "similar to the prolonged dream state (...) filled with hallucinating visions directly resulting from the mental content of the one who perceive them" (p. 57).

Thus, since the purpose of man is to exit the illusion, the natural tendency enforced by the doctrine of Hindu Advantin is to return to this plane of the lesser illusion; thus according to this cosmological perception, reincarnation in Hinduism is a law, the natural trend dictated by the order of the universe. The belief in reincarnation is a law with respect to this Eastern thought.

\section{The law of reincarnation is not a doctrine of} Bukôngo

The existence of the doctrine of reincarnation in Bukôngo is affirmed mostly by new Afrocentric movements calling for a return to traditional religion; two of these movements are Vuvamu and Bundu dia Kôngo. About this later, its founder Ne Muanda Nsemi was considered as the "'reincarnation" of Simon Kimbangu and Joseph Kasavubu" (Kihangu, 2011, p. 125). In a doctoral dissertation on Bundu dia Kôngo, Kihangu (2011) affirms:

This idea of 'the cycle of life and reincarnation' (...) is present in all religions. The only things that vary are the different forms that assume this 'return of the ancestors'; it can be an integral return of the personality of the defunct or of a part of the constituting principles of his personality (Kihangu, 2011, p. 182).

As we said above, our approach in this study is to handle the issue of reincarnation as an answer to the question: is it a law in African traditional worldview? Two approaches have been so far devised by the ISA for the demonstration of the fact that, contrary to its affirmation by the new Afrocentric movements, the belief in reincarnation is not a law in Bukôngo: the cosmological approach and the metaphysical one.

\section{The cosmological approach}

We have stated above that according to Izibili (2008), the word 'reincarnation' is un-African. Hemmert and Roudène (1983) write to this effect: "Not an Egyptian text refers to the transmigration of souls. It is true that the soul becomes Osiris could take any form. But it is not a question of reincarnation itself, that of the Hindus" (p. 31).

The basic characteristic of solar religion (as seen in ancient Egypt, Sumer and Bukôngo) is the hierarchical monotheism, the concept of the existence of one Supreme Being enthroned above lesser divinities that are his manifestations (Luyaluka, 2017a). This hierarchy of divinities is correlated by the hierarchy of the planes of existence.

Alluding to the bewilderment of the mûntu (the human being) in face of persistence of death beyond the grave, a Kôngo proverb says: ku bwala fwa, ku mpêmba fwa, kwe tuna tinina? [Where will we find a hiding knowing that death exists even in the world of the dead?] (Bahelele, 1977, p. 72). Now, if the dead keeps on dying in the plane next to ours, then there must be planes higher than our beyond where they have to go. Moreover the hierarchy of the divinities implies also the hierarchy of the possibilities of good: a greater good always awaits the dead mûntu on higher planes, i.e., in the companionship of the Gods or of higher Gods. 
The Egyptian book of the dead illustrates this last doctrine by the fact that the dead initiate, the Osiris Ani, having lived a life of purity in this lower plane, claims in the beyond the right to become an Osiris and to be accepted in the company of those Osiris who died before him, in the company of the Gods. This desire of the Egyptian initiate is traduced in Bukôngo by the saying: ku mpêmba kwa têkila wâku (Bahelele, 1956, p. 27) an expression which depicts the hope of a Mukôngo, a person belonging to the Kôngo ethnic, to be welcomed in the beyond (mpêmba, the world of holy-ancestors) by his dead kin.

Therefore, contrary to Hinduism, the cosmology of solar religion dictates the law of the progression of the mûntu towards higher planes, towards the greater good; the final destiny of the mûntu is a hope to become a pure Spirit like Kôngo, the primeval eponymous ancestor, i.e., the hope to fully develop the divinity, Kimahungu, which is potential in him (Fukiau, 1969). Therefore, the law of reincarnation is not a doctrine in Bukôngo. The cosmology of this African religion dictates rather the law of the continued progression of the dead towards higher planes of existence.

\section{The metaphysical approach}

Since the law of reincarnation is not a law of Bukôngo, it is appropriate to seek another interpretation of the phenomena which is assumed as the doctrine of reincarnation by the new Afrocentric movements. According to the ISA, there are metaphysically two phenomena that are often confused as scholars try to answer the question of the existence of the concept of reincarnation in ATR: the transmigration of souls and the transmigration of spirit.

- Transmigration of Soul: according to Chad Meiester (2009), "in its popular formulation, reincarnation is the view that the conscious self transmigrates from one physical body to the next after death" (p. 197). As the soul migrates from one body to another, the first body ceases to live while the second begins to. The two bodies cannot therefore be alive at the same time. This phenomenon is different from what we call the "transmigration of spirit".

- Transmigration of spirit: we find the phenomenon of the transmigration of spirit alluded in the Bible: "The Lord took of the spirit that was upon [Moses], and gave it unto the seventy elders: and it came to pass, that, when the spirit rested upon them, they prophesied, and did not cease" (Number 11:25).

What we learn from the transmigration of spirit is that the spirit, the power of discerning reality, can be transmigrated from an individual $A$ to a second one named $\mathrm{B}$; consequently the attributes, the abilities, of A are transmitted to B without being depleted in the sender A. According to informal conversations we had with one of the last initiates of the Kimpasi, the Kôngo sacerdotal initiatory academy that reigned south of the Congo River, the highest purpose of the initiatory education in the divine mystery is to prepare the initiate, through the purification of thought, to become receptive to the transmigration of spirit from the illuminated ancestors.

Alluding to this transmigration, the informant told us: "mpêve $i$ kulumukânga", i.e., the spirit descends on the initiate. In fact, seen in the solar epistemological context, any teaching involves the transmigration of spirit from the teacher to the taught; this is seen in the fact that even reason is perceived as being revelatory; the expression "to conceive an idea" doesn't exist in Kôngo language, one rather says: "thoughts came to me" ngîndu zi nduakidi, i.e., came from, or revealed by, higher planes (Luyaluka, 2016). Contrary to the transmigration of souls, in the transmigration of spirit the person whose spirit is communicated and the one, or the ones, who receives this spirit, continue both to be alive.

\section{Difference between the two phenomena}

The following three main differences can be established between the transmigration of soul and the transmigration of spirit:

- In the experience of the reincarnation the initial body ceases to live while the new body begins to exist; this is different from the phenomenon of the transmigration of spirit where the sender and the receiver or the receivers continue to exist along.

- The transmigration of soul happens between two bodies, while in the transmigration of spirit there may be several receivers.

- The essential result of the transmigration of spirit is that the attributes are shared with one or more other individuals without being depleted in the sender, while in reincarnation the attributes are totally depleted in the first body which dies.

\section{The deep meaning of the transmigration of spirit in Bukôngo}

In the context of the Kôngo culture, the concept of the transmigration of spirit from the dead to the here-living is linked to that of the name (nkûmbu) given to a newborn. Nkûmbu comes from the verb kûmba, "to be noised abroad, much talked of, be in every one's mouth (Bentley, 1885, p. 853), "to be famous" (kûmba, n.d.). The fact of giving a name to a child is called tômbola, meaning literally to raise; the name is called in this case "nkûmbu antômbola" or, as Wing (1956) has it described "zina di ntombola" (p. 220), zina and nkûmbu being synonymous.

When one inquires about the name that was attributed to a child, the usual expression voiced is: nkûmbu a nani batômbole, whose name has been raised up? This is very instructive, because we learn from this question that what is raised up from the world of the 
dead is not an ancestor, but his name, i.e., his fame, the good nature he has developed. It is therefore anomalous to speak of reincarnation, or the transmigration of soul, in this case.

It should be noted that the question can be reduced to a mere: nani batômbole, who has been raised up? However this doesn't mean that a soul is brought back to live here; this perception is ruled out by two concepts:

- For Lembe-Masiala (2007) "the Basolongo [a Kôngo sub-ethnic] say that nkûmbu a mûntu, $i$ mûntu to means that 'the name identifies the person' (p. 224); this Wing (1956) confirms by saying: "the name and the way of being are intimately linked" (p. 15). Thus the question nani batombole refers to the dead only figuratively.

- The practice of raising a name "tômbola nkûmbu" is not exclusively reserved to ancestors, the name of a here-living member of the family or a person related to the family and who is alive in this plane can also be raised (Wing, 1956).

It is also interesting to note the parallelism that can be established between this Kôngo concept of nkûmbu antômbola, the name that rises up the fame of an ancestor, and the Egyptian custom of the ka-name that Majeed (2012) explains in the following manner: "A $k a$-name is given to a person on the basis of the basic attribute that the bearer's specific soul is conceived to have. In this sense also, the $k a$, is an abstract personality of the individual" $(\mathrm{p} ; 11)$.

\section{Transmigration of spirit in other african cultures}

As we said it above, Bukôngo is the continuity of the solar religion that characterized the ancient civilizations of Sumer and Egypt; this fact is evidenced by the immersion of Bukôngo in solar epistemology and its correlation with the KCA, the systematic natural theology of solar religion. Therefore, the immersion of African ethnics in solar epistemology and their southward migrations from the confines of ancient Egypt imply that every trend of traditional religion in Africa can be explained in terms of the devolution of the solar religion, i.e., of its continuation, Bukôngo. Therefore, the Kôngo concept of the transmigration of spirit can explain what is often mistakenly taken as the reincarnation in other African cultures south of Sahara.

\section{Transmigration of spirit among the Bomitaba}

According to Mr. M. Madzoko, a native of the northern province of Likouala (Republic of Congo) with whom we had an informal talk, when a baby was born among the Bomitaba (an ethnic of Likouala to which Mr. Madzoko belongs) the parents were in no hurry of finding a name for him. They inquired with the ancestors to know who "came through this child". The parents and the whole family waited until the child in a dream announced the name of the ancestor who "came" through his birth. Is this conception of the Bomitaba a belief in the law of reincarnation?

Properly explained, this Bomitaba practice reflects not a belief in the law of reincarnation but rather a belief in the transmigration of spirit of the dead. According to my informant, the transmigration of spirit among the Bomitaba resembles the Kôngo practice and involves the following characteristics:

- Unlike the transmigration of soul, the ancestor who is supposed to have "come" through the birth of the child does not stop living in the beyond, but instead becomes the protector of the newborn.

- Like among the Bakôngo, this phenomenon can occur between the ancestor and several other children of the family. I'm named after my late grand-father "Luyaluka", but I'm not the only one to possess his name in the extended family, as we were three to bear the same name simultaneously.

- The qualities developed by the ancestor are assumed to arise in the newborn child. I and my two cousins were all expected to manifest the qualities of our venerated grandfather.

All these traits demonstrate that the phenomenon alluded by the Bomitaba is consistent with the experience of the transmigration of spirit.

\section{Transmigration of spirit among the Yoruba}

Speaking of reincarnation among the Yoruba of Nigeria Ọsanyìnbí \& Falana (2016) affirm the following facts:

Reincarnation is the belief that the dead family members come back to life, as a new child into family where they previously belong when they were alive. These are usually identified through resemblance, dreams or divination to confirm reincarnations of particular ancestors, and are given names such as Babatunde ("father returns") or Yetunde ("mother returns").These ancestors are invoked to help their descendants (Osanyinbi \& Falana, 2016, p. 62).

One should note the parallelism between this conception of the Yoruba and the concept of the Bomitaba. The fact that "these ancestors are invoked" while they are supposedly "reincarnated" in the children shows that what is referred here is not in reality a transmigration of soul, because to be invoked the ancestors must be alive in the beyond. Therefore the phenomenon described here is in reality a transmigration of spirit and not a reincarnation as the authors falsely assume.

\section{Transmigration of spirit among the Esan}

The Esan are people of a southwestern Nigerian ethnic. Speaking of the concept of reincarnation among this ethnic Izibili (2008) explains that: "(..) in Esan, only ancestral spirits can reincarnate; and they may do so in more than one child. 
This is clearly seen in the personality and character of the new person" (p. 107).

We learn clearly here that:

- This transmigration is made between the ancestor and one child or more.

- The personality and the character of the ancestor are seen in the newborn.

In view of these two characteristics, it is easy to understand that this author describes the transmigration of spirit and confuses it with reincarnation.

\section{Transmigration of spirit among the Igbo}

The Igbo are an ethnic of Nigeria. Writing about their belief in reincarnation, Stevenson (1985) informs us that:

Many Igbos believe that a single deceased person may reincarnate contemporaneously in two or more physical bodies (...). Indeed, a person may reincarnate in as many as ten or twelve later-born bodies. This process in one sense involves a duplicating of the discarnate soul. However, it also entails a "splitting" of the soul, because different qualities of character, and even different physical traits of the discarnate person, may become expressed in the several reincarnation of that person (Stevenson, 1985, p. 18).

Whenever this author speaks of the "splitting" of the soul, for Ogbujah (2008) this situation "neither proves ubiquity of existence nor destroys or diminishes the life of the departed in the spirit-world" (p. 430) and he adds that "Various authors, after careful examination of the issues involved, point to the resurgence of character traits in the descendants of an ancestor" ( $p$. 425).

What should be retained from these two scholars about the belief of this Nigerian ethnic group is that:

- Transmigration can occur between an ancestor and one or more newborn.

- There is a resurgence of character and traits in the descendants, but the ancestors is neither destroyed nor diminished.

These two characteristic beliefs of the Igbo culture are consistent with the doctrine of the transmigration of spirit as observed in Kongo culture. Therefore, Obgujah (2008) is right to conclude that Igbo belief in reincarnation: "it is very clear that the Igbo belief in does ilo-uwa not express the content of reincarnation, and cannot be equiparated with it" ( $p$. 427).

\section{The transmigration of soul among the Luo}

According to the Encyclopedia of African religion, "the Luo (Jaluo and Joluo) are an important ethnic group in Kenya, eastern Uganda, and northern
Tanzania" (Asante, 2009b, p. 390). About the belief in reincarnation among these Africans the encyclopedia informs us that:

The child is usually named between birth and age 2 after an ancestor appears in a dream to an adult member of the family. Actually this means that the person who does good deeds and is well respected will return in a dream to the living and thus begin the process of reincarnation again. When the child is named, he or she will take on some of the characteristics of the returned ancestor. Thus, if the ancestor was kind, the child becomes a kind person in life; if argumentative, the same. The named ancestor becomes the individual's guiding spirit throughout his or her life (Asante, 2009b, p. 391).

We learn from this account of a custom of the Luo that:

- The child takes some of the characteristics of the ancestor.

- The ancestors become the guiding spirit of the child; this implies that the child and the ancestor are both alive; this is in contradiction with the transmigration of soul.

These two characteristics of the naming practice of the Luo are consistent with the belief in the transmigration of spirit rather than with the law of reincarnation.

\section{Reincarnation versus transmigration of spirit}

All the cases that have been examined above are clear indications that the phenomenon of the transmigration of spirit is confused by many scholars as being the proof of the presence of the doctrine of reincarnation in Africa. Whereas the Kôngo culture shows clearly that what is brought back from the world of the dead is the "name" of an ancestor, i.e., his fame, expectedly the character in which he excelled.

However, though this old custom related to the naming of newborn is not a proof of the presence of the law of reincarnation in Africa, nevertheless, there are cases where the belief in reincarnation is involved in Africa.

\section{The free choice to reincarnate}

The question that we attempt to answer in this section is: why within the framework of African cosmological conception of progression towards higher planes of existence can someone choose to reincarnate? Two perceptions can be provided as a response to this query.

Reasoning analogically from the school systems, which, like the African cosmology, are governed by the law of the progression of the successful pupils towards higher levels, we can assume that one can make the choice to reincarnate on this lower plane 
because he failed, in his previous earthly life, to properly work towards the manifestation of his divinity, the Kimahungu, the temporal expression of the Verb; thus he has found himself in the beyond in a dire situation whereby he could not cope with higher exigencies of spirituality.

On the other hand, the horizontal and vertical relationships which are ontological among the Africans in the framework of the cosmological unity of the visible and the invisible (Nkata, 2002), teach us that those who are in our plane of existence live for the ancestors and the ancestors also live for those they left on this plane. Thus, it is natural to think that the ancestors can choose a person to reincarnate in order to accomplish a saving mission for the benefit of those of this plane of existence.

The two possible cases provided can never be taken as evidences of the operation of the law of reincarnation in African cultures. They are rather denote the acceptation of the belief in reincarnation by the one who "comes back" to this lower plane of existence, an exception to the law of the progression to higher planes of existence.

\section{CONCLUSION}

When the issue of the reincarnation in African culture is handled, the scholars always try to the answer the following question: is it a belief in the African traditional religion (ATR)? In this paper we sustained that the main question should be: is reincarnation a law in the ATR?

We have chosen to base our study on Bukôngo, the Kôngo religion, because it is has been demonstrated to be the continuation of the solar religion that characterized the ancient civilizations of Egypt and Sumer; therefore the immersion of African ethnics in the solar epistemology as ancient Egypt and Sumer and their southward migrations imply that the different trends of ATR can be understood as the devolutions of solar religion, i.e. of Bukôngo its continuation.

We used comparative study to demonstrate the difference which exists between the conceptions of reincarnation in Hindu Advantin and in Bukôngo. This comparison reveals that the belief in reincarnation is a law according to the cosmology of the Hindu Advantin while Bukôngo rather dictates the law of the progression of the dead towards higher planes of existence.

After having established the difference between reincarnation, as the transmigration of soul, and the transmigration of spirit, we have demonstrated that what is often assumed as the reincarnation of an ancestor in Bukôngo is in reality the transmigration of spirit, the natural process by which the ancestor shares his attributes with a child and even becomes his protector. Therefore what is brought back from the world of the dead is not an ancestor, but his fame.

Through comparative study of Bukôngo and some African ethnics (the Bomitaba, the Esan, the Yoruba, the Igbo and the Luo), we have demonstrated that what is assumed to be the process of reincarnation by many scholars is in reality the doctrine of the transmigration of spirit.

However, our study didn't rule out the existence of reincarnation in ATR; it has rather been shown to be an exception to the law of progression towards higher planes of existence due to the failure of the reincarnated to cope with the spiritual demands of the higher plane of existence or his acceptance to return to this lower plane in order to come rescue the hereliving.

\section{REFERENCES}

- ARMSTRONG, K. (1993). A HISTORY OF GOD.
RETRIEVED
https://www.spiritualiteit.co.za/boekresensie-
armstrong-a-history-of-god.pdf.

- Asante, M. K. (2009A). Ancestors. In M. K. ASANTE \& A. MAZAMA (EDS.), ENCYCLOPEDIA OF AFRICAN RELIGION (PP. 45-52). THOUSAND OAKS, CA: SAGE.

- $\quad$ Asante, M. K. (2009B). Luo. In M. K. Asante \& A. MAZAMA (EDS.), ENCYCLOPEDIA OF AFRICAN RELIGION (PP. 390-392). THOUSAND OAKS, CA: SAGE.

- BAHELELE N. (1977). LUSANSU YE FU BIA N'KONGO, KINSHASA: CENTRE PROTESTANT D'EDITIONS ET DE DIFFUSION.

- BAHELELE, N. (1956). KINZONZI YE NTEKOLO ANDI MAKUNDU. KINSHASA: CENTRE PROTESTANT D'EDITIONS ET DE DIFFUSION.

- BAndzouzi, A. (2002). Le KIMBANGUISME. PARIS, FRANCE: EKI.

- Bentley, H. (1895). The Dictionary and GRAMMAR OF THE KÔNGO LANGUAGE. LONDON, ENGLAND: BAPTIST SOCIETY.

- Cuvelier, P. (2006). la Mythologie MÉSOPOTAMIENNE ET LES RÉCITS DU DÉLUGE. RETRIEVED FROM HTTP://WWW.NORMALESUP.ORG/ PCUVELIER/WWW MYTHES/EXPOSEMYTHOLOGIEMESOPOTAMIENNE.P DF.

- Dungen, W. V. D. (2016). The Theology of Memphis. $\quad$ Retrieved from http://www.maat.sofiatopia.org/memphis.htm.

- $\quad$ EVANS-Wentz, W. Y. (1969). LE LIVRE DES MORTS TIBETAIN, PARIS: ADRIEN MAISONNEUVE.

- Fukiau, A. (1969). LE MUKONGO ET LE MONDE QUI L'ENTOURAIT, KINSHASA: ONRD. 
Kiatezua Lubanzadio Luyaluka; Saudi J. Humanities Soc Sci, Jan, 2022; 7(1): 21-28

- HeMmert, D. \& Roudène, A (1983). METEMPSYCOSE, REINCARNATION ET SURVIE, GENEVE: FARMOT.

- IZIBILI, M. A. (2008). REINCARNATION "IROSO" IN ESAN: A MYTH OR REALITY. STUD TRIBES TRIBALS, 6(2), 105-109.

- JAMES, G. G. M. (1954). STOLEN LEGACY. RETRIEVED FROM http://www.sacredtexts.com/afr/stle/stle12.htm

- JiMOH, S. L. (2012). REINCARNATION: REAPPRAISING THE BELIEF OF YORUBA MUSLIMS WITHIN THE CONTEXT OF ISLAMIC ORTHODOXY. ILORIN JOURNAL OF RELIGIOUS STUDIES, 2(1), 81-96.

- Kihangu, G. M. (2011). BUNDU Dia KonGo, UNE RESURGENCE DES MESSIANISMES ET DE L'ALLIANCE DES BAKONGO? (DOCTORAL DISSERTATION). UNIVERSITY OF GENT, BELGIUM.

- Kramer, S. N. (1981). HiSTORY BEGINS AT SUMER. PHILADELPHIA: UNIVERSITY OF PENNSYLVANIA PRESS.

- KÛMBA. (N.D.) DICTIONNAIRE (LEXIQUE) KIKONGOFRANÇAIS. RETRIEVED HTTP://WWW.NGUNGA.COM/9.HTML.

- Lembe-Masiala, N. (2007). LE KAANDU CHEZ LES BASOLONGO DU BAS-CONGO (RDC). (DOCTORAL DISSERTATION). UNIVERSITY OF GENT, BELGIUP.

- LuyaluKA, K. L. (2014). Religion AND SCIENCE CONVERSION POSSIBILITY: TOWARDS THE FORMULATION OF A SYSTEMATIC THEODICY OF AFRICAN TRADITIONAL RELIGION AND ITS REINTERPRETATION OF EMPIRICAL COSMOLOGY. JOURNAL OF PAN AFRICAN STUDIES, 7(7), 108-139.

- Luyaluka, K. L. (2016). AN Essay ON NATURALIZED EPISTEMOLOGY OF AFRICAN INDIGENOUS KNOWLEDGE. THE JOURNAL OF BACK STUDIES, 47(6), 497-523.

- LUYAlUKA, K. L. (2017A). AFRICAN INDIGENOUS RELIGION AND ITS ANCIENT MODELS REFLECTIONS OF KONGO MONOTHEISM. THE JOURNAL OF BACK STUDIES, 48(2), 165-189.
- Luyaluka, K. L. (2017B). THE SOlAR COSMOLOGICAL INTERPRETATION OF THE EgYPTIAN Nut, SHU, GEb SCENE. SAUdi JOURNAL OF HUMANITIES AND SOCIAL SCIENCES, 2(8), 669 676

- MajeED, H. M. (2012). AN EXAMINATION OF THE CONCEPT OF REINCARNATION IN AFRICAN PHILOSOPHY. (DOCTORAL DISSERTATION). UNIVERSITY OF SOUTH-AFRICA, SOUTH-AFRICA.

- Maspero, G. (N.D.). A history of EGYPT, CHALDEA, SYRIA, BABYLONIA AND ASSYRIA, VOL. 1, PART B. RETRIEVED HTTP://WWW.GUTENBERG.ORG.

- MeISTER, C. (2009). INTRODUCING PHILOSOPHY OF RELIGION. LONDON, ENGLAND: ROUTLEDGE.

- NkATA, J. M. (2002). LA MYSTIFICATION FONDAMENTALE, LUBUMBASHI: PRESSE UNIVERSITAIRE.

- Obgujah, C. N. (2008). The Idea of human destiny in Africa: The Igbo experience. Retrieved from http://journal.unpar.ac.id/index.php/melintas/article /viewFile/970/953

- Osanyìnbí, O. B., \& Falana, K. (2016). AN EVALUATION OF THE AKURE YORÙBÁ TRADITIONAL BELIEF IN REINCARNATION. RETRIEVED FROM http://file.scirp.org/pdf/OJPP_2016022216182079. pdf.

- $\quad$ Pew Forum on Religion \& Public Life. (2011). ISLAM AND CHRISTIANITY IN SUB-SAHARAN AFRICA. POLICY ISSUES, WASHINGTON D.C: PEW FORUM ON RELIGION AND PUBLIC LIFE.

- RAWLINSON, G. (1886). ANCIENT EGYPT. RETRIEVED FROM http://www.gutenberg.org.

- Sayce, A. H. (1903). The Religions of ancient Egypt and Babylonia, T. \& T. Clark, Edinburgh, UK, 310.

- Wayne, H. H. (1991). RESURRECTION, REINCARNATION, AND HUMANNESS. BIBLIOTHECA SACRA, 148(590), 132-145.

- WING, J. V. (1956). ETUDES BAKÔNGO (2ND ED.). BRUXELLES: LIBRARIE FALK FILS. 